\title{
Opção pela vasectomia e relações de gênero
}

\author{
The option for vasectomy and implications \\ for gender relations
}

Nádia Maria Marchi 1

Augusta Thereza de Alvarenga 2

Maria José Duarte Osis 3

Luis Bahamondes 1

\footnotetext{
1 Centro de Atenção Integral à Saúde da Mulher, Departamento de Tocoginecologia, Universidade Estadual de Campinas. C. P. 6181, Campinas, $S P$

13084-971, Brasil. nmarchi@hawk.com.br bahamond@caism.unicamp.br

2 Departamento de Saúde Materno-Infantil da

Faculdade de Saúde Pública, Universidade de São Paulo.

Av. Dr. Arnaldo 715,

São Paulo, SP

01246-904, Brasil. atal@usp.br

3 Centro de Pesquisas Materno-Infantis de Campinas. C. P. 6181 Campinas, $S P$ 13084-971, Brasil. mjosis@cemicamp.org.br
}

\begin{abstract}
A qualitative study was performed to: investigate the process that leads couples to decide for vasectomy; characterize the gender relations involved in this process; and identify sources of information on vasectomy. Semi-structured interviews were conducted with 20 couples who had requested vasectomy at the outpatient clinic of the Center for Integrated Women's Health Care, State University in Campinas, São Paulo, Brazil. A structured form was used to collect social, economic, and demographic data. The content analysis technique was used for data analysis. The majority of couples opted for vasectomy as a last resort after attempting numerous other contraceptive methods, not always successfully. The emerging gender relations showed fluctuation between: (1) a more rigid, quasi-patriarchal model characterized by male predominance in the family's decision-making and (2) a more ambiguous model in relation to reproductive decisions, whereby women assumed responsibility for contraception until the situation became untenable, at which point men faced up to the unavoidable necessity of sterilization. At this point the male partners felt they should collaborate.
\end{abstract}

Key words Vasectomy; Contraception; Gender Relations

Resumo Realizou-se um estudo qualitativo para conhecer o processo de decisão de casais pela vasectomia, as relações de gênero envolvidas e identificar as fontes de informação sobre o método. Foram feitas entrevistas semi-estruturadas com vinte casais que solicitaram a vasectomia no Ambulatório de Reprodução Humana do Centro de Assistência Integral à Saúde da Mulher, Universidade Estadual de Campinas. Para a análise dos dados, utilizou-se a técnica de análise do conteúdo. A maioria dos casais optou pela vasectomia como último recurso anticoncepcional, após ter utilizado outros métodos, nem sempre com sucesso. Os homens se auto-atribuíram a iniciativa de se submeterem à cirurgia dada a impossibilidade de criarem mais filhos. Pessoas significativas para eles foram as principais fontes de informação, suscitando interesse pelo método e afastando os temores. As relações de gênero desveladas oscilaram entre um modelo quase patriarcal, com o predomínio dos homens nas decisões da vida familiar, e um modelo ambíguo nas decisões reprodutivas, em que as mulheres haviam assumido a responsabilidade da anticoncepção até que, diante da inevitabilidade da esterilização, os homens consideraram que deveriam colaborar.

Palavras-chave Vasectomia; Anticoncepção; Relações entre Gênero 


\section{Introdução}

Tradicionalmente, a preocupação em regular a fecundidade esteve centrada na perspectiva de controlar a natalidade via fecundidade feminina. Esse conceito passou a conviver, a partir da década de 70, com o de planejamento familiar, que procurava enfatizar os benefícios dessa prática não só para a saúde das mulheres, mas também das famílias e da sociedade em geral. Com base na emergência do Programa de Assistência Integral à Saúde da Mulher (PAISM) no Brasil, a concepção do planejamento familiar tornou-se preponderante, dominando as discussões nessa área, inclusive como forte argumento contrário à adoção de uma política demográfica para o país (Alvarenga \& Schor, 1998; Osis, 1998a; Rocha, 1993). Nos anos 80, surgiu o conceito de saúde reprodutiva, muito mais amplo, que ganhou destaque a partir das Conferências de Cairo e Beijing, em 1995 (Alcalá, 1995; Alvarenga \& Schor, 1998). Pretende dar abrangência às relações de gênero implícitas no exercício dos direitos reprodutivos, incorporando, portanto, a idéia de que a regulação da fecundidade deve ser tratada em relação a homens e mulheres concomitantemente (Barzelatto \& Hempel, 1990).

O conceito de saúde reprodutiva evidencia que a preocupação com a reprodução humana se constitui em uma construção social, em que se determinam os papéis de homens e mulheres para além das chamadas diferenças biológicas (Barbieri, 1990). Nesse sentido, esse conceito expõe criticamente os Programas de Planejamento Familiar que, exclusivamente, são direcionados às mulheres. Essa seria a razão pela qual, ainda hoje, tais programas oferecem ou dispõem de métodos anticoncepcionais quase exclusivamente para mulheres. A evidência e os debates acerca dos direitos sexuais e reprodutivos suscitam a preocupação de incorporar efetivamente os homens nas atividades relacionadas às questões de saúde reprodutiva. A partir da atuação dos movimentos de mulheres, que procuram dar relevância às relações de gênero implícitas nas ações voltadas à regulação da fecundidade, o papel dos homens na contracepção tem se tornado tema freqüente de discussão (Pitanguy, 1994).

Existe a necessidade de conhecer em profundidade as motivações e as maneiras como os homens, enquanto sujeitos sociais, encaram sua posição no processo reprodutivo. De fato, porém, não é muito o que se sabe a esse respeito. Por isso, na última década, vem se dando uma maior ênfase a esse aspecto, tornando-se tema relevante as relações entre masculinidade e reprodução (Arilha, 1999).

Nos últimos anos, muito se tem falado dos novos paradigmas da masculinidade e da paternidade. O conceito de masculinidades, ao invés de masculinidade, tem se expandido e ganhado os diferentes foros de discussão. Salienta-se que, apesar de ainda prevalecer o protótipo tradicional do homem ativo, forte, capaz de realizar o trabalho físico, de lutar na guerra e de penetrar o corpo da mulher, poucos são os que, efetivamente, conseguem cumprir plenamente essa expectativa. Dessa forma, os diferentes homens, nos diferentes contextos de vida, adaptam esse modelo tradicional de masculinidade, preservando o que lhe é possível e que lhe garanta o reconhecimento de seus pares. Por exemplo, em muitos ambientes em que os jovens incorporam em seu discurso novos paradigmas de masculinidade, quando se casam, reassumem o modelo aprendido de seus pais (AVSC International/IPPF, 1999).

Essa convivência de modelos está presente na área da reprodução, indicando como ambígua a posição dos homens nas decisões reprodutivas, na medida em que sua percepção acerca de seus papéis nessa área também tende a oscilar de acordo com os diferentes modelos de masculinidade e de paternidade. Embora do ponto de vista genético, homens e mulheres são e se reconhecem como participantes do processo reprodutivo, este não ocupa o mesmo lugar no imaginário feminino e masculino. Uma pesquisa (Arilha, 1999), com homens dos estratos sociais médio e baixo, indicou que a preocupação deles com a reprodução é relevante para construir a sua identidade moral, mas está relacionada ao campo do social e não ao seu próprio corpo.

Empiricamente, observa-se que a participação dos homens na anticoncepção costuma ser escassa (Carvalho et al., 2000; Rogow et al., 1991), e uma das causas apontadas para isso é a falta de opções contraceptivas para homens. Ao contrário das mulheres, que têm várias opções de métodos anticoncepcionais, os homens contam, basicamente, com o preservativo e a vasectomia (Mundigo, 1995). Embora se considere que a população masculina participa também da anticoncepção por intermédio das mulheres que usam métodos comportamentais e preservativo feminino (Blaney, 1997; Piet-Pelon et al., 1999), o fato é que esses métodos recebem pouca ou nenhuma atenção, uma vez que não se fornecem informações sobre eles, levando ao seu uso inadequado (M. Díaz, J. Díaz \& J. Townsend, comunicação pessoal). 
Com respeito à vasectomia, sua prevalência no Brasil, apesar de ter aumentado nos últimos anos, é ainda baixa: em 1986, 0,8\% das mulheres unidas referiram que seus companheiros estavam vasectomizados (Arruda et al., 1987), enquanto que a última Pesquisa Nacional sobre Demografia e Saúde (PNDS), mostrou uma prevalência de 2,6\%. A maior prevalência de vasectomia foi identificada em São Paulo: 6,1\% (BEMFAM/Macro International, 1997). Isso confirma o que se tem observado nos últimos anos. Uma avaliação do PAISM realizada na área metropolitana de São Paulo e no interior do estado, apontou crescimento na prevalência de vasectomia entre 1988 e 1991. Para a região de Campinas, houve uma diferença significativa, passando de $1,4 \%$ para $3,7 \%$ entre as mulheres unidas (Hardy et al., 1995). Estudos realizados na cidade de Campinas, Estado de São Paulo, apontaram que a prevalência de vasectomia ultrapassava os $10 \%$ (Cecatti \& Faúndes, 1996; Duarte, 2000).

Em Campinas, desde 1986, a Disciplina de Urologia da Faculdade de Ciências Médicas da Universidade Estadual de Campinas (UNICAMP) começou a oferecer a vasectomia, independentemente do Serviço de Reprodução Humana do Centro de Assistência Integral à Saúde da Mulher (CAISM). Este, embora tenha iniciado suas atividades de planejamento familiar em 1977, até aquela data não havia conseguido implementar um atendimento eficiente à demanda por vasectomia. Isso se devia, ao menos em parte, ao fato de esse ambulatório estar inserido no Departamento de Tocoginecologia, voltado exclusivamente às mulheres, cabendo à Urologia o atendimento de homens na área sexual e reprodutiva.

Entretanto, a partir de 1993, o próprio Ambulatório de Reprodução Humana buscou ampliar o leque de opções contraceptivas, instituindo o Programa de Vasectomia, que foi facilitado pela introdução da técnica chamada sem bisturi (Castro, 1983; Li et al., 1991). Desde então a vasectomia passou a ser oferecida com os demais métodos que são disponibilizados no ambulatório, a todo casal que demanda o serviço em busca de um método definitivo de contracepção e que preencha os requisitos estabelecidos. Ao ser oferecida em igualdade de condições a outros métodos, observou-se um aumento da demanda da mesma. Tal tendência pode ser constatada no período de 1986 a 1992, quando foram realizadas 526 cirurgias, em comparação com 797 realizadas entre 1993 e 1995.

Esses dois exemplos de serviços, que passaram a oferecer a vasectomia com sucesso em sua rotina assistencial, colocam a possibilida- de de que esta prática ocorra também em outros. Entretanto, pensar a implementação voltada para os homens deveria envolver a preocupação de evitar os erros cometidos em relação às mulheres. Especialmente, é preciso inseri-los na perspectiva de saúde reprodutiva. É necessário ter presente que não se trata de trocar a esterilização feminina pela masculina, mas de permitir às pessoas a escolha livre e informada de um método contraceptivo, o que implica dispor de todas as opções para homens e mulheres e não apenas de algumas. Nesse contexto, apresenta-se como importante a constituição de tais serviços, o entendimento das motivações, da perspectiva e das expectativas dos homens quanto à anticoncepção.

Tendo em vista tal nível de preocupação, os objetivos do presente estudo foram conhecer o processo de decisão de casais pela vasectomia, as relações de gênero nele envolvidas, bem como identificar as fontes de informação que os levaram a se interessar pela vasectomia.

\section{Participantes e métodos}

O estudo realizado foi de natureza qualitativa, adotando-se a técnica da história oral do tipo temático (Meihy, 1996), isto como recurso para proporcionar o entendimento da situação vivida por casais que passaram pela experiência do processo de decisão acerca da opção pela vasectomia como método contraceptivo definitivo.

Foram selecionados 20 casais que procuraram o Serviço de Reprodução Humana do CAISM, da UNICAMP, com a intenção de realizar a vasectomia. Esse ambulatório faz parte do Sistema Único de Saúde (SUS), que prevê o atendimento universal e gratuito à população, sendo que as pessoas ali atendidas podem ter acesso a todas as alternativas contraceptivas disponíveis no país, sem qualquer custo para elas. Os casais selecionados estavam inscritos no Programa de Vasectomia do CAISM/UNICAMP, que atende as solicitações de esterilização cirúrgica masculina, e passaram por um processo que durou cerca de três meses, conduzido por uma equipe multidisciplinar, que inclui médicos, enfermeiras, assistentes sociais e psicólogas. Nesse período, os casais receberam ação educativa sobre métodos anticoncepcionais e orientação específica sobre a vasectomia, podendo mudar sua decisão de esterilizar-se em qualquer momento antes da cirurgia, ou mesmo naquele momento.

A média de idade foi de 32,7 anos para os homens e 32,1 para as mulheres. A média de 
anos de escolaridade foi de 6,3 para os homens e 6,9 para as mulheres, o que equivale a terem cursado até a $6 \underline{\text { a }}$ ou $7 \underline{\text { a }}$ série do ensino fundamental. Igual número de homens e mulheres (seis) cursou pelo menos uma série do ensino médio, sendo que três mulheres e dois homens completaram-no. Ninguém tinha curso superior. Todos os homens e 11 mulheres realizavam um trabalho remunerado na época das entrevistas. A média de renda familiar foi de $\mathrm{R} \$$ 991,50 (US\$ 486.00). Dezessete casais eram casados civilmente e três viviam em união consensual. O número médio de filhos por casal foi de 2,5, com variação de 1 a 6 , cujas idades eram de 45 dias a 18 anos. Dois casais tinham apenas um filho e estavam solicitando a vasectomia por problema sério de saúde da mulher, que contra-indicava absolutamente uma nova gravidez: uma fizera transplante renal e a outra sofrera uma trombose venosa grave.

Os casais foram entrevistados entre janeiro e maio de 1999. Inicialmente, entrevistou-se cada membro do casal separadamente, no momento do primeiro contato com o Ambulatório de Reprodução Humana. Os homens também foram entrevistados num segundo momento, após terem agendado a cirurgia.

Os dados foram levantados por meio de entrevistas, utilizando um formulário semi-estruturado, para caracterização sócio-econômica e demográfica dos participantes e roteiros temáticos para a pesquisa em profundidade, ambos pré-testados. Os roteiros foram definidos com base nos objetivos propostos, visando a desvelar o problema sob investigação. O pressuposto de que as decisões reprodutivas são relacionais e decorrem da dinâmica das relações de gênero (Figueroa-Perea, 1998), foi o referencial teórico levado em consideração para a elaboração desses roteiros. Prepararam-se perguntas de partida e de aprofundamento a fim de guiar as entrevistas em profundidade. As entrevistas foram gravadas e, posteriormente, transcritas.

No processo de tratamento dos dados, as entrevistas, após a transcrição, foram lidas, destacando-se as unidades de significado. Com base nos objetivos da pesquisa, identificou-se um conjunto de categorias para a análise, utilizado na leitura das transcrições para marcar as diferentes porções do texto. Em seguida, redigiu-se um resumo descritivo para cada uma das entrevistas, com base nos quais se procedeu a análise do conjunto dos dados levantados.

Para a análise das falas dos casais, foi utilizada a técnica de análise de discurso buscando desvelar as unidades de significado ou temas identificados nos depoimentos dos mesmos, tendo em vista compreender o modo de pro- dução social de tais falas, bem como detectar os valores de referência e os padrões de comportamento presentes nos discursos dos sujeitos (Bardin, 1977; Marcolino, 1994; Martins \& Bicudo, 1989; Minayo, 1996; Oliveira, 1996). Com base na identificação desses temas, estabeleceram-se categorias gerais e específicas, conforme sua freqüência de aparição (Domingues, 1997), que passaram a dar significado aos discursos dos casais que tinham optado pela vasectomia como método definitivo de contracepção.

Para o presente trabalho, foram analisadas as seguintes categorias temáticas - unidades de significado - que passaram a estruturar a análise dos discursos:

- Processo de decisão pela vasectomia: compreende o conhecimento sobre o método e os procedimentos pelos quais os homens passariam; as fontes de informação, o surgimento e a evolução da idéia da esterilização masculina no âmbito do casal; expectativas de benefícios decorrentes da opção pela vasectomia.

- Relações de gênero: visualizadas valendo-se da percepção e da experiência dos casais quanto à responsabilidade da anticoncepção, exercício da sexualidade e da liberdade sexual das mulheres em relações de poder e papéis familiares, trabalho da mulher.

A participação dos casais foi voluntária, assegurando-lhes o sigilo sobre a fonte das informações, de forma que os instrumentos de coleta de dados e as fitas gravadas foram identificados somente por um número. Todos os casais que aceitaram participar assinaram um termo de consentimento livre e esclarecido. $\mathrm{O}$ estudo foi aprovado pelo Comitê de Ética em Pesquisa da Faculdade de Ciências Médicas, UNICAMP.

\section{Resultados}

\section{Fontes de informação}

A maioria dos casais informou que procurou o serviço de saúde para solicitar a vasectomia porque lhes foi indicado por amigos, familiares ou funcionários da universidade em que se encontra o serviço. Apenas dois casais haviam sido referidos por outros serviços de saúde: um de posto de saúde e outro de um hospital municipal da mesma região.

Segundo as falas dos casais, suas concepções sobre a vasectomia foram sendo construídas por meio de informações de amigos, parentes, vizinhos, colegas, mas, antes de passarem pela orientação do programa, observou-se que 
não sabiam como ela era realizada. Foi mencionado pelas mulheres que os homens costumam sentir-se constrangidos em perguntar detalhes sobre a cirurgia a amigos e colegas.

“Eu pesquisei um pouco (...) eu conversei com os amigos que fizeram, que eu tenho bastante amigo, primo que mora em São Paulo, Limeira, eles vêm em casa, eles falam pra mim: 'vai rapaz', tudo eles, a maioria são tudo operado. Então fui criando confiança que eles falaram que é normal, que fica até melhor, não sei o quê, falei 'então, então vou fazer"' (Homem).

\section{Processo de decisão}

Em geral, os casais relataram que a idéia de fazer a vasectomia partiu do homem em face do número de filhos que já tinham e da impossibilidade de criar mais crianças. Na maior parte dos casos, essa idéia já vinha se formando há mais de um ano e foi se cristalizando a partir de conversas do homem com amigos/colegas/parentes que já tinham realizado a vasectomia, ou conheciam pessoas que haviam feito e testemunhavam que era um bom método, seguro, simples de fazer e que não alterava a sexualidade masculina. Os casais tenderam a reconhecer que essas opiniões foram significativas para eles, mas que a decisão propriamente dita foi tomada pelos dois, conversando, debatendo sua situação.

"A cirurgia já vem de muitos tempos, eu querendo fazer, certo? Só que até agora eu não tive condições de fazer (...) mas a conversação minha com a minha esposa, com alguns colegas meus, eu achei melhor fazer" (Homem).

Nessa discussão que culminou com a decisão pela vasectomia, a única alternativa colocada a esse método foi a laqueadura. Entretanto, foram os homens que a descartaram, porque consideravam que ela faz mal à saúde das mulheres, bem como pode torná-las frígidas. Além disso, a vasectomia foi preferida por ser uma cirurgia menor, que traz poucos riscos e incômodos para os homens, enquanto a laqueadura é muito mais onerosa para as mulheres.

“(...) Porque a mulher sofre mais, né? Já foi feito duas cesáreas, agora vem outra, então pra mim é mais simples" (Homem).

Aos casais também foram feitas perguntas específicas sobre sua opinião quanto a métodos anticoncepcionais que implicam participação masculina: preservativo masculino, tabela/calendário e coito interrompido. Em geral, não se observou rejeição dos homens à utilização desses métodos, porém, nenhum dos casais considerara a possibilidade de utilizálos ao invés de fazer a vasectomia, fundamen- talmente porque não acreditavam em sua eficácia, além de outros aspectos negativos que mencionaram. Os sentimentos mais expressos foram a dúvida quanto à eficácia do preservativo, o desconhecimento acerca da tabela, intuindo grande possibilidade de falha, e o "desconforto" do coito interrompido. As mulheres tenderam a expressar sentimentos semelhantes aos dos homens. Entre elas, porém, foi mais explícita a disposição de usar o preservativo, caso fosse necessário.

Nos casos em que a decisão de fazer a vasectomia era antiga, na maioria das vezes, a sua efetivação foi retardada pela falta de acesso ao método, porque esses casais não tinham dinheiro para a cirurgia. Poucos homens relataram que o processo de decisão pela vasectomia inclui a superação de preconceitos a respeito do que significaria para eles serem vasectomizados. Um deles disse que superou esses preconceitos porque viu a necessidade de buscar o que era bom não só para ele, mas também para a esposa. A referida esposa mencionou que este foi conversar com o médico da empresa em que trabalhava e este o esclareceu de forma a que tomasse a decisão.

“(...) A gente tinha assim um preconceito muito grande, né, sobre essa cirurgia (...) a gente tem que olhar não só o lado da gente mas também o lado da esposa (...) a dificuldade que a gente passa no momento, a crise do país, então a gente não pode fazer com que espalha muitos filhos, né (...), eu tomei a decisão, achei que vai ser muito válido para mim" (Homem).

Outro homem afirmou que havia desistido da cirurgia há um tempo, com medo, por ter ouvido más informações sobre as conseqüências da mesma. A esposa contou que haviam dito ao homem que ele poderia "virar bicha”. O homem venceu esse medo, superou a opinião alheia e decidiu operar-se quando a mulher engravidou novamente, uma vez que eles já não queriam mais filhos.

“(...) Muita gente dava conselho pra fazer, outros falavam que não era bom porque (...) a gente podia largar da mulher (...) mas eu acho que não é possível a gente com seis filhos ainda vai se largar (...) e deixar filho pelo mundo (...)"(Homem).

“(...) Ah, ele tinha um pouco de dúvida, porque às vezes os colegas falam: Aí, vai virar bicha, né (...) esses negócios assim, teve dúvida (...)" (Mulher).

O principal benefício, que pareceu decisivo aos casais para que optassem pela vasectomia, foi a segurança de não engravidarem, o que resultaria em uma vida sexual tranqüila e mais satisfatória, sem precisar usar qualquer 
outro recurso. Alguns mencionaram especificamente o aspecto positivo de não precisarem usar preservativo nas relações sexuais o que, por vezes, era desagradável para o homem e para a mulher. Os homens enfatizaram também que, uma vez que eles estariam esterilizados, as suas mulheres não precisariam usar outros métodos que faziam mal à sua saúde, de maneira que a vida do casal e da família seria melhor. Além disso, alguns referiram-se ao fato de que suas esposas tinham um grave problema de saúde, que contra-indicava absolutamente a gravidez, de forma que a vasectomia era o recurso mais seguro. Na fala das mulheres também apareceu com ênfase que, na opção pela vasectomia, pesou a intenção do companheiro de poupar a sua saúde, evitando-lhe mais sofrimentos. Uma delas disse que o companheiro sempre teve vontade de fazer a vasectomia porque se lembrava do sofrimento da mãe, que fizera laqueadura, e não queria que ela passasse pelo mesmo.

“(...) Ela [a mãe] que fez a cirurgia e não o pai dele, e ele viu, acho que desde moço, um sofrimento que ela teve, que ela passa até hoje, por conta dela ter feito o desligamento" (Mulher).

Os casais entendiam que a vasectomia seria o melhor método para eles diante de suas circunstâncias de vida. Tenderam a afirmar que só recomendariam a vasectomia a outros casais depois de fazer a cirurgia e, mesmo assim, sua recomendação seria no sentido de que essas pessoas fossem buscar informação para tomar uma decisão bem consciente para não se arrependerem.

\section{Relações de gênero}

Questões referentes às relações de gênero foram retidas dos depoimentos, por categorias específicas, quais sejam: responsabilidade pela anticoncepção, liberdade sexual das mulheres, relações de poder e trabalho da mulher.

\section{Responsabilidade pela anticoncepção}

Houve consenso de que a responsabilidade pela anticoncepção deve ser partilhada pelo casal, que ambos devem conversar e procurar as melhores soluções. Os serviços de saúde deveriam estar disponíveis para orientar os casais, mas estes é que deveriam tomar a iniciativa de ir procurar informações e métodos.

“A responsabilidade é dos dois, do casal (...) Porque eu acho que é dos dois, dos dois, né, é uma conversa entre os dois, saber o que deve ser feito ou não, não um só tomar uma decisão e sacrificar uma pessoa ou outra" (Homem).
Um entrevistado disse explicitamente que a responsabilidade da anticoncepção deve ser do homem porque, caso ocorra a gravidez, ele é quem deverá assumir o sustento da criança e da mulher, porque ela vai ter de cuidar do filho. A esposa desse homem, porém, considerou que a responsabilidade é do casal.

“(...) A responsabilidade é do homem (...) porque a mulher sempre arca com as conseqüências (...) o homem (...) ele foge da responsabilidade, seja consciente ou inconsciente, porque se ele tiver que assumir aquele filho, ele vai assumir de qualquer forma" (Homem).

\section{Liberdade sexual das mulheres}

Os entrevistados afirmaram que não viam qualquer aspecto negativo no fato de as mulheres tomarem a iniciativa das relações sexuais. Para eles, isso fazia parte da liberdade sexual de que as mulheres gozam hoje em dia e era algo de que gostavam. Muitos deles, porém, disseram que isso não acontecia com freqüência. No geral, eles referiram que a iniciativa era deles, na maior parte das vezes. Colocada a hipótese de a mulher não querer ter a relação, a tendência dos participantes foi dizer que procuravam compreender os seus motivos, embora ficassem um pouco aborrecidos. Quando o inverso acontecia, eles relataram que as companheiras também eram compreensivas. Em geral, não houve discrepância no relato das mulheres a esse respeito. Apenas uma disse que o companheiro ficava "bravo" quando ela não queria ter relações, e um homem disse que a esposa "brigava" até que ele se estimulasse a ter relação.

“(...) Ah, você num vai pegar a mulher e dar porrada na cara dela se fala que não quer ter relação, fazer o quê?" (Homem).

Em geral, tanto os homens quanto as mulheres vincularam a liberdade sexual da mulher ao ambiente da relação com o companheiro, em termos de tomar a iniciativa das relações e demonstrar prazer. Um dos homens disse que as mulheres devem ser livres para procurar relações sexuais, mesmo fora do casamento, com os mesmos direitos que os homens. Outro mencionou que, enquanto a mulher é solteira pode fazer o que quiser, mas deve ser orientada pelos pais sobre como evitar a gravidez.

“(...) Liberdade de escolha [para a mulher] (...) a mulher está mais livre... a partir daí, o momento em que ela decide arrumar essa ou aquela pessoa, ela realmente está decidida, ela sabe o que quer" (Homem).

“(...) Eu não sou livre assim, porque eu acho que a mulher depois que casa (...) ela é livre, 
mas tem que ser tudo junto com a família, não é querer dar uma de mocinha" (Mulher).

Uma entrevistada enfatizou que a partir do momento em que casa, a mulher deve viver para agradar o companheiro, para que ele não arrume outras mulheres.

“(...) Se você casou com ele e está vivendo com ele, tem mais é que agradar ele, porque hoje em dia a vida está tão difícil, está tão revoltado o mundo, que ele vai arrumar outra, não está nem aí (...)" (Mulher).

De modo geral, os casais consideraram que sua vida sexual era satisfatória e tinham expectativa de que fosse melhorar mais depois da cirurgia, porque desapareceria o medo da gravidez. Nenhum dos entrevistados mencionou que, depois da cirurgia, estaria em busca de relações extraconjugais, mas disseram que, se isso porventura ocorresse, eles usariam preservativo para prevenir-se de doenças sexualmente transmissíveis (DST)/AIDS. O mesmo se observou entre as mulheres, acrescentando-se que elas salientaram que não julgavam necessário passar a usar o preservativo com o companheiro, porque confiavam neles, mas que, se elas viessem a ter outro parceiro, usariam.

\section{Relações de poder}

Com respeito às relações de poder no âmbito do casal e na vida familiar, identificou-se dois padrões diferentes. Um, em que o homem se declarou como líder, a autoridade na casa, quem toma as decisões e assume toda a responsabilidade, mesmo solicitando e considerando as opiniões da esposa. Outro, em que o homem afirmou que "delega" a autoridade à mulher, confiando-lhe as decisões cotidianas, como, por exemplo, aquelas que se relacionavam com a manutenção da casa e o pagamento de contas rotineiras, confiando que ela não iria fazer nada que pudesse prejudicar a família. As decisões de maiores repercussões eram tomadas em conjunto, sob a liderança do homem. Em nenhum dos modelos, os homens se autoqualificaram como autoritários, nem as mulheres o fizeram. Sua argumentação foi a de que é natural que haja uma liderança dentro da casa e que esta seja, em geral, do homem.

“(...) Eu não sou mandão, mas a gente, um casal, sempre um ou outro toma esse lado (...) agora, da situação financeira em casa é eu, isso aí não tem jeito" (Homem).

“(...) Não é questão de mandar, né, mas o homem tem que ser autoridade dentro da casa, não querer ser machista, mas tem que colocar as coisas na frente (...) tem que dar um passo na frente a fazer todas as coisas ... o homem é o che- fe dentro de casa (...) a partir do momento que você constrói uma família, você tem que ter uma autoridade na sua casa" (Homem).

Com respeito às obrigações e responsabilidades de cada membro do casal, a tendência dos homens e mulheres entrevistados foi referir que partilhavam tudo, desde as coisas mais simples, como a limpeza da casa, até as mais complexas, como a educação dos filhos, a compra de bens, a mudança de emprego. Especialmente quanto à educação dos filhos, os homens enfatizaram que dividiam com as mulheres essa responsabilidade, porque elas passavam mais tempo com as crianças e podiam melhor acompanhar o seu desenvolvimento. Apenas um homem disse que essa responsabilidade era dele, mas que ele solicitava que a esposa, que ficava em casa, supervisionasse as lições das crianças, mesmo porque ela possuía maior grau de instrução que ele.

"A decisão da educação dos meus, dos filhos nossos, somos nós dois, certo? Só que ela convive mais com eles do que eu, que eu trabalho e ela fica em casa, então quem tem mais condição de corrigir é (...) ela, agora se tiver alguma coisa grave, aí ela tem que comunicar (...) ela comunica a mim, a gente vai conversar com a criança, né?" (Homem).

\section{Trabalho das mulheres}

De modo geral, os entrevistados concordaram que é positivo as mulheres trabalharem fora de casa, porque isso lhes dá independência econômica e/ou permite que elas possam ajudar a família, se houver necessidade. Porém, ressalvaram que isso não pode prejudicar a criação dos filhos. Quanto a esse aspecto, houve homens que disseram que não queriam que os filhos ficassem na casa de outras pessoas, e outros que apontaram a necessidade de que as crianças fiquem em bons lugares para que as mulheres possam assumir um trabalho fora de casa. As entrevistadas expressaram opiniões no mesmo sentido, sendo que uma parte delas havia parado de trabalhar porque tinha os filhos pequenos e planejava retomar quando eles crescessem um pouco mais. Na fala das mulheres, na maioria das vezes, o trabalho fora de casa não foi determinado pela busca de realização pessoal, mas visando a essencialmente auxiliar o companheiro nas necessidades da família.

“(...) Desde que ela possa trabalhar, não tem nada que "estrove" ela trabalhar, seria uma boa, inclusive (...) minha esposa trabalhou (...) aí veio outro filho (...) as crianças na escola, a escola é longe, ela tem que levar e tem que buscar" (Homem). 
“Nos dias de hoje é necessário, né, é muito difícil o marido que dê conta de tudo que precisa. Então, não é assim, uma independência, é uma necessidade" (Mulher).

Somente um dos homens enfatizou que o ideal seria a mulher poder ficar em casa, cuidando dos filhos, sem precisar preocupar-se com mais trabalho, fora de casa. Ele lamentava que não pudesse assumir completamente a responsabilidade de sustentar a família, o que obrigava a mulher a trabalhar fora de casa.

“(...) Eu não acho bom a mulher trabalhar fora... ela ficou para trabalhar em casa, mas como a gente não pode, então tem que trabalhar os dois (...)" (Homem).

\section{Discussão}

Ficou evidente que os casais participantes deste estudo chegaram ao serviço de saúde com a decisão já tomada de fazer a vasectomia, e que essa decisão não estava embasada em informações técnicas precisas sobre o método, uma vez que, antes de passarem pelo programa, eles nem sabiam como a cirurgia era feita. Observou-se também que suas fontes de informação foram pessoas significativas para eles (amigos, colegas, vizinhos, parentes), não se mencionando, em geral, profissionais e/ou serviço de saúde. Isso indica a lacuna que existe na atenção primária à saúde quanto à regulação da fecundidade. As pessoas tendem a não ver os serviços básicos como fontes de informação na área da anticoncepção.

O fato de os casais chegarem ao programa de vasectomia com a decisão já tomada, significa também, uma maior dificuldade para prover orientação, sendo essa situação bastante comum nos serviços de planejamento familiar, inclusive em países desenvolvidos, constituindo uma barreira no processo de aconselhamento. As pessoas constroem a sua representação de um determinado método, valendo-se de informações de diversas fontes, corretas ou não, com base nas quais fazem a sua escolha. Assim, o serviço de saúde tende a ser procurado como fonte para obtenção de um método já escolhido. Esse fato constitui-se num desafio aos profissionais para abordarem essas pessoas com sucesso, e oferecer-lhes uma oportunidade de voltarem a refletir acerca de sua escolha contraceptiva com base em novas informações e, muitas vezes, em face da necessidade de correções dos conceitos já cristalizados (Walsh et al., 1996).

Neste estudo observou-se que a opção pela vasectomia transcendia o conhecimento das características do método em si. Os casais optaram por ela porque desejavam um método eficaz, seguro, com os menores riscos possíveis. Ao mesmo tempo, referiram experiências negativas com outros métodos, sendo que boa parte delas foi considerada como prejudiciais à saúde das mulheres. A representação da vasectomia que os casais tinham quando chegaram ao serviço, construída a partir da troca de vivências cotidianas, fazia dela o método ideal em face às suas experiências anteriores e expectativas presentes e futuras quanto ao controle da reprodução. Parece que pouco lhes importava a forma como seria feita a cirurgia. Bastava saber da experiência de outras pessoas como eles, e por isso mesmo confiáveis, para terem certeza de que o resultado seria positivo: não precisariam mais se preocupar com a anticoncepção e poderiam ter uma vida sexual satisfatória. Para os homens, a opinião e a experiência de outros homens - amigos, colegas, conhecidos, parentes - com a vasectomia parece ter sido decisiva para torná-los convictos de que estavam fazendo a opção correta e que não sofreriam qualquer prejuízo em sua saúde e masculinidade (Castro, 2000; Viveros, 1998). Essa mesma perspectiva é a que tem sido apontada por mulheres que solicitam a laqueadura (Minella, 1998; Osis, 1998b; Serruya, 1996; Vieira, 1998).

Com respeito à construção dessa representação da vasectomia como método desejado e ideal, outro ponto relevante a considerar é o de que os casais não discutiram a possibilidade de usar outro método, exceto a laqueadura. Esta, semelhantemente ao verificado em estudos realizados somente com mulheres (M. J. D. Osis, G. A. Duarte \& S. F. Bento, comunicação pessoal), foi referida como a única opção similar à vasectomia quanto à sua eficácia, porém em desvantagem no que diz respeito à facilidade de realização e aos prejuízos à saúde. Os participantes do presente estudo deixaram claro que preferiam a vasectomia ao invés da laqueadura por pensarem no bem-estar das mulheres, o que foi também observado por Castro (2000), entre homens de São Paulo que solicitavam vasectomia.

Por outro lado, é importante frisar que a opção pela vasectomia foi feita, principalmente, porque os homens tomaram a iniciativa de fazê-la. Aparentemente, isto poderia ser interpretado como um sinal de compartilhamento das decisões reprodutivas. Porém, não se pode deixar de lembrar que, até o momento em que decidiram que poderiam fazer vasectomia, esses homens não tiveram uma participação ativa nos assuntos ligados à contracepção, o que 
foi referido tanto por eles quanto por suas companheiras. No processo que culminou com a decisão, atribuída ao casal, de fazer a vasectomia, os homens passaram a ter uma postura ativa apenas no estágio final, quando não se vislumbravam mais outras opções. A negociação quanto ao método a ser usado, depois que se haviam esgotado as possibilidades da mulher usar alguma forma de contracepção, se impôs dentro dos limites práticos das poucas opções visualizadas, e da lógica com que se davam as relações de poder no âmbito do casal.

Nesse contexto, é necessário discutir os papéis de gênero envolvidos nas decisões contraceptivas. Por um lado, evidencia-se que, nessa área, os homens tendem a assumir responsabilidades apenas à medida que se vêem diante de não quererem/não poderem ter mais filhos e já se ter esgotado as tentativas de alcançar isto através do uso de métodos temporários, principalmente ou exclusivamente pelas mulheres, restando apenas a opção da esterilização. Nesse caso, eles procuraram poupar as companheiras dos "males" da laqueadura. Por outro lado, parece que eles praticamente não vislumbraram formas de participar da regulação da fecundidade, apenas de seu encerramento. Arilha (1999) enfatiza que os homens, na verdade, consideram que a liderança dos processos reprodutivos é das mulheres, ao mesmo tempo em que é deles a responsabilidade de sustentar a família. Dessa forma, é possível entender porque eles apenas "intervêm” efetivamente nas decisões reprodutivas quando acreditam que chegaram aos limites de sua capacidade como provedores.

Em relação aos homens, historicamente, em nossa cultura, vem predominando o ser "bom provedor" como elemento distintivo da masculinidade (Engle \& Leonard, 1998). Arilha (1999), porém, argumenta, com base em estudo realizado com homens de São Paulo, dos estratos médio e baixo, que esse modelo do homem-provedor está em transformação, o que vem acarretando aos homens várias dificuldades para se autoposicionarem quanto aos seus papéis de gênero. Segundo essa autora, mesmo quando existe na vida cotidiana uma divisão das tarefas domésticas e da responsabilidade financeira, os homens continuam a sentir-se responsáveis pela manutenção da autoridade moral familiar. Esse aspecto foi amplamente observado nos resultados aqui apresentados, em que os entrevistados manifestaram aceitação e valorização do trabalho das mulheres, bem como se disseram intensamente participativos no cuidado com os filhos, mas, ainda assim, se auto-atribuíram toda a responsabili- dade quanto à família. Eles se reconheceram como os líderes e os responsáveis pelo bom andamento da vida familiar, muito embora tenhase observado que eles "delegavam" às mulheres várias tarefas, especialmente a educação dos filhos.

Para melhor compreender essa situação, é importante frisar que, especificamente com respeito à saúde sexual e reprodutiva, é possível perceber que nas últimas duas décadas tem havido um intenso movimento em prol da incorporação dos homens como atores, que devem ser ativos nesses processos, especialmente em face dos grandes desafios que a epidemia de AIDS suscitou (Population Reference Bureau, 1998). Isso certamente tem contribuído para que a própria sociedade aceite e considere desejável que os homens assumam tal postura, o que claramente está refletido no discurso deles. Porém, o mesmo não se verifica ainda quanto às questões da vida familiar. Se, por um lado, as mulheres parecem desejar que os homens compartilhem a responsabilidade de educar os filhos, assim como a "gerência dos negócios da família", por outro, quando isto começa a ocorrer pode haver ambivalência e tensão, tanto no âmbito das relações do casal quanto na comunidade em geral (Engle \& Leonard, 1998).

Em síntese, ao considerar a participação masculina nas escolhas contraceptivas, não se pode deixar de assinalar que, do ponto de vista da provisão de serviços de saúde sexual e reprodutiva que atendem aos homens, e de métodos de participação masculina, não se pode dizer que os avanços tenham sido compatíveis com a grande ênfase discursiva acerca da necessidade de levá-los a ser mais participativos. No Brasil, a tendência continua sendo a de tentar alcançar os homens pelos serviços destinados primariamente ao atendimento das mulheres, centralizando os esforços na oferta do preservativo - visando principalmente a prevenção de DST/AIDS - e da vasectomia, quando o casal deseja um método definitivo.

Nessa situação, para propiciar a participação efetiva dos homens na contracepção, não basta a oferta de preservativos e de vasectomia. Faz-se necessário proporcionar-lhes um processo educativo mais abrangente, voltado para a orientação em contracepção, que discuta com eles mesmos as relações de gênero envolvidas nas decisões reprodutivas (Castro, 2000; Díaz et al., 2000). Ou seja, primariamente é necessário dar a oportunidade de os homens se posicionarem como co-protagonistas do processo reprodutivo por inteiro, propiciando-lhes também o esclarecimento de suas dúvidas e a des- 
mistificação dos conceitos e preconceitos que possam ter quanto à sua participação na anticoncepção. Vale frisar que não se trata apenas de prover informação personalizada para homens, mas, muito mais, de prover um ambiente favorável à reflexão acerca de seus papéis reprodutivos.

\section{Agradecimentos}

Projeto de pesquisa apoiado pela Fundação de Amparo à Pesquisa do Estado de São Paulo (projeto 99/09148-1).

\section{Referências}

ALCALÁ, M. J. (org.), 1995. Compromisos para la Salud y los Derechos Sexuales y Reprodutivos de Todos: Marcos de Acción. New York: Family Care International.

ALVARENGA, A. T. \& SCHOR, N., 1998. Contracepção feminina e política pública no Brasil: Pontos e contrapontos da proposta oficial. Saúde e Sociedade, 7:87-110.

ARILHA, M., 1999. Homens, saúde reprodutiva e gênero: O desafio da inclusão. In: Questões de Saúde Reprodutiva (K. Giffin \& S. H. Costa, org.), pp. 455-467, Rio de Janeiro: Editora Fiocruz.

ARRUDA, J. M.; RUTENBERG, N.; MORRIS, L. \& FERRAZ, E. A., 1987. Pesquisa Nacional sobre Saúde Materno-Infantil e Planejamento Familiar - PNSMIPF - Brasil 1986. Rio de Janeiro: Sociedade Civil Bem-Estar Familiar no Brasil/Instituto para Desenvolvimento de Recursos.

AVSC INTERNATIONAL/IPPF (International Planned Parenthood Federation - Western Hemisphere Region), 1999. Male Participation in Sexual and Reproductive Health: New Paradigms. Oaxaca: AVSC International/IPPF.

BARBIERI, T., 1990. Sobre géneros, prácticas y valores: Notas acerca de posibles erosiones del machismo en México. In: Normas y Prácticas Morales y Cívicas en la Vida Cotidiana (J. R. Vaiz, org.), pp. 83-105, México, DF: Universidad Nacional Autónoma de México.

BARDIN, L., 1977. Análise de Conteúdo. Lisboa: Edições 70 .

BARZELATTO, J. \& HEMPEL, M., 1990. Reproductive Health: A Strategy for the 1990's. New York: Ford Foundation.
BEMFAM (Sociedade Civil Bem-Estar Familiar no Brasil)/MACRO INTERNATIONAL, 1997. Pesquisa Nacional sobre Demografia e Saúde: Brasil, 1996. Rio de Janeiro: BEMFAM/MACRO International.

BLANEY, C. L., 1997. Involving men after pregnancy. Network, 17:22-25.

CARVALHO, M. L. O.; PIROTTA, K. C. M. \& SCHOR, N., 2000. Apoio: A forma predominante de participação masculina na regulação da fecundidade do casal. Saúde e Sociedade, 9:61-76.

CASTRO, M. P. P., 1983. Vasectomia. São Paulo: Editora Rocca.

CASTRO, M. P. P., 2000. Vasectomia. In: Contracepção: Promoção da Saúde Sexual e Reprodutiva. (R. P. Andrade, M. Poli, A. Petracco, K. M. Morais \& A. F. Camargos, org.), pp. 175-207, Rio de Janeiro: Revinter.

CECATTI, J. G. \& FAÚNDES, A., 1996. O Impacto das Altas Taxas de Cesárea Sobre a Fecundidade de uma População. Um Estudo de Coorte Retrospectiva em Campinas, Brasil, 1995. Relatório de pesquisa apresentado à Fundação Ford. Campinas: Centro de Pesquisas Materno-Infantis de Campinas.

DIAZ, M.; LOPES, J. C.; TENÓRIO, T. \& BRASILEIRO, I. G., 2000. Processo de orientação em planejamento familiar. In: Contracepção: Promoção da Saúde Sexual e Reprodutiva. (R. P. Andrade, M. Poli, A. Petracco, K. M. Morais \& A. F. Camargos, org.), pp. 27-34, Rio de Janeiro: Revinter.

DOMINGUES, C. M. A. S., 1997. Identidade e Sexualidade no Discurso Adolescente. Dissertação de Mestrado, São Paulo: Faculdade de Saúde Pública, Universidade de São Paulo. 
DUARTE, G. A., 2000. Contracepção e Aborto: Perspectiva Masculina. Dissertação de Mestrado, São Paulo: Faculdade de Saúde Pública, Universidade de São Paulo.

ENGLE, P. L. \& LEONARD, A., 1998. Los padres como compañeros en la crianza de los hijos In: $\mathrm{La} \mathrm{Fa}$ mília en la Mira: Nuevas Perspectivas sobre Madres, Padres e Hijos (J. Bruce, ed.), pp. 49-69, New York: Population Council.

FIGUEROA-PEREA, J. G., 1998. Algunos elementos para interpretar la presencia de los varones em los processos de salud reproductiva. Cadernos de Saúde Pública, 4(Sup. 1):87-96.

HARDY, E.; FAÚNDES, A.; BAHAMONDES, L.; OSIS, M. J. \& FAÚNDES, D., 1995. Fatores de riesgo de arrepentimiento de esterilización quirurgica detectables antes de la ligadura. In: XIV Reunión de la Asociación Latinoamericana de Investigadores en Reproducción Humana (ALIRH), Anales, p. 38, Santo Domingo: PROFAMILIA.

LI, S.; GOLDSTEIN, M.; ZHU, J. \& HUBER, D., 1991. The no-scalpel vasectomy. Journal of Urology, 145:341-344.

MARCOLINO, C., 1994. Trajetória da Mulher em Direção à Esterilização Cirúrgica Feminina: Um Estudo Fenomenológico. Dissertação de Mestrado, São Paulo: Faculdade de Saúde Pública, Universidade de São Paulo.

MARTINS, J. \& BICUDO, M. A. V., 1989. A Pesquisa Qualitativa em Psicologia: Recursos e Fundamentos Básicos. São Paulo: Editora Moraes/Editora da PUCSP.

MEIHY, J. C. S. B., 1996. Manual de História Oral. São Paulo: Edições Loyola.

MINAYO, M. C. S., 1996. O Desafio do Conhecimento: Pesquisa Qualitativa em Saúde. 4a Ed. São Paulo: Editora Hucitec/Rio de Janeiro: ABRASCO.

MINELLA, L. S., 1998. Aspectos positivos e negativos da esterilização tubária do ponto de vista de mulheres esterilizadas. Cadernos de Saúde Pública, 14(Sup. 1):69-79.

MUNDIGO, A. I., 1995. Papéis Masculinos, Saúde Reprodutiva e Sexualidade. São Paulo: Fundação MacArthur.

OLIVEIRA, D. C., 1996. A Promoção da Saúde da Criança: Análise das Práticas Cotidianas Através do Estudo de Representações Sociais. Tese de Doutorado, São Paulo: Faculdade de Saúde Pública, Universidade de São Paulo.
OSIS, M. J. D., 1998a. PAISM: Um marco na abordagem da saúde reprodutiva Brasil. Cadernos de Saúde Pública, 14(Sup. 1):25-32.

OSIS, M. J. D., 1998b. Esterilização e gravidez na adolescência: Fatores inter-relacionados. In: Seminário Gravidez na Adolescência (E. M. Vieira, M. E. L. Fernandes, P. Bailey \& A. McKay, org.), pp. $67-$ 73, São Paulo: Associação Saúde da Família.

PIET-PELON, N. J.; ROB, U. \& KHAN, M. E., 1999. Men in Bangladesh, Indian and Pakistan: Reproductive Health Issues. Dhaka: Karshaf Publishers.

PITANGUY, J., 1994. Feminist politics and reproductive rights: The case of Brazil. In: Power and Decision: The Social Control of Reproduction (G. Sem \& R. C. Snow, org.), pp. 101-122, Boston: Harvard University Press.

POPULATION REFERENCE BUREAU, 1994. Inquietudes Femeninas: Las Mujeres Escriben Sobre la Participación de los Hombres en la Familia. Washington, DC: Population Reference Bureau.

ROCHA, M. I. B., 1993. Política Demográfica e Parlamento: Debates e Decisões sobre o Controle da $\mathrm{Na}$ talidade. Campinas: Núcleo de Estudos da População, Universidade Estadual de Campinas.

ROGOW, D.; BRUCE, J. \& LEONARD, A., 1991. Man/ Hombre/Homme: Respuestas a las Necesidades de la Salud Reproductiva Masculina en América Latina. New York: Population Council.

SERRUYA, S., 1996. Mulheres Esterilizadas: Submissão e Desejo. Belém: Núcleo de Altos Estudos Amazônicos, Universidade Federal do Pará/Universidade do Estado do Pará.

VIEIRA, E. M., 1998. O arrependimento após esterilização feminina. Cadernos de Saúde Pública, 14 (Sup. 1):59-68.

VIVEROS, M., 1998. Decisiones reproductivas y dinámicas conyugales: El caso de la elección de la esterilización masculina. In: Masculinidades y Equidad de Género en América Latina (T. Valdés \& J. Olavarría, org.), pp. 146-157, Santiago de Chile: Facultad Latinoamericana de Ciencias Sociales.

WALSH, J.; LYTHGOE, H. \& PECKHAM, S., 1996. Contraceptive Choices: Supporting Effective Use of Methods. London: Family Planning Association.

Recebido em 12 de março de 2002

Versão final reapresentada em 25 de outubro de 2002 Aprovado em 28 de fevereiro de 2003 